\title{
Eduardo De Filippo a Catalunya
}

\author{
Francesc Massip \\ Universitat de Tarragona \\ Institut del Teatre de Barcelona
}

\begin{abstract}
La recepció de De Filippo a Catalunya ha estat escassa: a banda de La gran il.lusió duta a escena per Herman Bonnin (1988), L’art de la comèdia dirigida per Jordi Mesalles (1992) o la Filumena Marturano que Alfred Lucchetti va traduir i protagonitzar el 1995, només quan Belbel muntà Dissabte, diumenge i dilluns al Teatre Nacional de Catalunya (2002) es va desvelar als catalans tot el potencial i la riquesa dramàtica de De Filippo amb una posada en escena vibrant $i$ audaç que va estar en cartell dues temporades seguides, i que va deixar una singular empremta en l'última peça belbeliana: Forasters (2004), on ressona el tema del deteriorament de les relacions familiars, així com els efectes de fantasmagoria escènica $\mathrm{i}$ els aspectes metateatrals que tan interessaven al napolità, tot plegat amb personatges de gruix i una singular ambició expressiva, que no oblida mai al gran públic. El teatre d'Eduardo permet operacions d'actualització i escenificació molt dinàmiques, d'aquí la seva vigència $i$ adaptabilitat a èpoques $i$ cultures ben distintes.
\end{abstract}

Paraules clau: dramatúrgia contemporània, connexions teatrals italocatalanes.

\begin{abstract}
The reception of De Filippo in Catalonia has been sparse: La gran il.lusió put on the stage by Herman Bonnin (1988), L'art de la comedia directed by Jordi Mesalles (1992) or the Filumena Marturano that Alfred Lucchetti translated and played the leading role in 1995. It was only when Belbel staged Dissabte, diumenge i dilluns at the Teatre Nacional de Catalunya (2002) that the Catalan public was exposed to the potential and dramatic richness of De Filippo with vibrant and audacious scenery which was used two seasons running. It also left its mark on the latest Belbel piece: Forasters (2004), resounding with the theme of the deterioration of family relationships, as well as the effects of the scenic phantasmagoria and the meta-theatrical aspects that so interested the Neapolitan, interwoven with characters with depth and a singular expressive ambition, that never forgets the general public. The theatre of Eduardo enables updating methods and encourages very dynamic scenographies, and from there comes the validity and adaptability to very different periods and cultures.
\end{abstract}

Key words: contemporary drama, Italian-Catalan theatrical connections. 
Sempre hem considerat Eduardo De Filippo un dels homes de teatre clau de la Itàlia del segle XX, al costat de Luigi Pirandello i Dario Fo, i per això hem celebrat els pocs muntatges que de les seves obres s'han fet al nostre país.

Així com Josep M. de Sagarra va poder portar Pirandello a Barcelona, traduir i presentar algun dels seus textos i extreure'n bones lliçons (pensem en Galatea), quan calia dur De Filippo (els anys cinquanta i seixanta) la situació política no ho permeté i, malgrat l'estrena en castellà (única llengua en què s'autoritzava l'escenificació d'autors estrangers) de Filumena Marturano l'any 1951, al Teatre Borràs, per la companyia de Pepita Serrador, De Filippo va ser pràcticament un desconegut a casa nostra. És cert que l'afirmació internacional del seu teatre, encetada amb el muntatge de la Filumena al Teatre Vakhtangov de Moscou (1950), va culminar la dècada dels setanta, especialment amb l'escenificació de Sabato, domenica e lunedì al teatre Old Vic de Londres, amb Lawrence Olivier com a protagonista i sota la batuta de Franco Zeffirelli (1973).

El primer muntatge en català de què tenim notícia és La gran il.lusió ( La grande magia), traduiida per Narcís Comadira per a la posada en escena que en va fer Herman Bonnin el 1988 al Centre Dramàtic de la Generalitat (Romea). El 1992, Jordi Mesalles dirigia L'art de la comèdia (en traducció de Pere Puértolas) al SAT de Sant Andreu, que no vam veure. Sí que veiérem i comentàrem la Filumena Marturano que va dirigir Frederic Roda Pérez el 1995 al Teatre Goya, traduïda i protagonitzada per Alfred Lucchetti (Avui, 25-I-1995). El mateix any a València, una ciutat que també té molts punts de contacte amb la capital partenopea, s'estrenava Nàpols milionària al Teatre Micalet, de la mà de Joan Peris i amb traducció de Maria Bayarri i Júlia Benavent.

Però és evident que, si un muntatge va revelar als catalans tot el potencial i la riquesa dramàtica de De Filippo, aquest va arribar el 2002 de la mà de Sergi Belbel i la seva versió i direcció de Dissabte, diumenge i dilluns, que, amb una posada en escena vibrant i audaç, un repartiment esplendorós i una actuació brillant, va suposar l'èxit més sonat i indiscutible del TNC fins avui, de manera que va haver de reposar-se la temporada següent (2004).

Menys interès tingué una segona incursió de Mesalles a De Filippo, que va escenificar Un barret de copa i Sik-Sik, l'artífex màgic, el 2003, a l'Espai Lliure, en versió de Núria Furió. Recordem que Sik-Sik ja l'havia presentat al Grec de 2001 Carlo Cecchi al capdavant del Teatro Garibaldi de Palerm i amb un magnífic Arturo Cirillo com a protagonista, mentre que el 2005, en el marc de la segona edició d' «Els Napolitans», que coordina Dario De Vita, Bruno Garofalo, al capdavant de la Compagnia Media Aetas, ens ha ofert Napoli nella tempesta, i el Nuovo Teatro Nuovo Questi fantasmi, una de les obres més significatives de De Filippo que ara protagonitza el director i actor italoamericà John Turturro (Souls of Naples) i que, sota la direcció de Roman Paska, tindrà a Nàpols la seva estrena europea (gener de 2006). 


\section{La napolitanitat com a valor universal}

De Filippo deia: «M’adono que les comèdies, com més són en napolità, més universals resulten». I és que un dels principals valors del teatre d'Eduardo és la seva extraordinària capacitat d'observació del seu entorn més proper, la seva minuciosa i detallada anàlisi dels tipus que l'habiten i de les situacions vitals en què es mouen, fins al punt que Fellini el definia com un «espeleòleg de Nàpols». Aquesta captació de la realitat més immediata l'acosta a les veritats fonamentals que, d'altra banda, ha anat transmetent el teatre de la tradició. Però és que, a més, com declarava Eduardo, els napolitans de manera espontània parlen i actuen com a intèrprets en el gran escenari que són els carrers de Nàpols, no debades un dels tractats sobre el gest més sucosos és degut al canonge proixità Andrea De Jorio (La mimica degli antichi investigata nel gestire napoletano, 1832). D’altra banda, Nàpols conté, com un espill matusserament argentviuat, totes les grandeses i misèries del món contemporani.

Quan l'expressió d'allò local és afinada i es fa amb la punteria d'Eduardo, s'arriba a tocar el nervi de les qüestions humanes essencials que no canvien gaire d'un lloc a un altre.

D'altra banda, les cultures locals poden tenir una importància i una expansió si aconsegueixen expressar la seva veritable identitat i, molt especialment, si tenen la fortuna de trobar autors, actors i directors d'alt nivell. I en aquest sentit, Eduardo ha fet possible que el teatre napolità tingués la seva veu al món i s'expressés en un registre universal.

Per això és possible la traducció/adaptació dels textos de De Filippo, almenys a una cultura mediterrània tan propera com la catalana, on, a banda dels vincles històrics d'ençà del Magnànim, hem compartit durant segles aspectes com els rituals culinaris (a l'entorn del ragú o de la paella dominical), aromes i sabors d'exquisit tast (des dels vins fins als macarrons passant per la pizza, aquí "coc en tomata» o "coca de recapte»), cançons solars i marineres, així com també uns usos de viure al carrer empentats pel bon temps, una idea dels valors aglutinants de la família, del seu funcionament solidari però també asfixiant, etcètera.

A més a més, hi ha aspectes de la napolitanitat que Barcelona ha pogut entendre i explicar millor que cap altra ciutat de la península Ibèrica, per les moltes coses que té en comú amb Nàpols. Per exemple, el fet de ser dues antigues capitals avui desposseïdes d'Estat, desplaçades dels centres de decisió pels poders centralistes, però que han mantingut en molts aspectes la vitalitat creativa i la preeminència artística.

Si la cultura catalana va crear el primer heroi modern de ficció, Tirant lo Blanc - escrit entre la Nàpols del Magnànim i la Barcelona de Carles de Viana-, la cultura napolitana va forjar l'antiheroi per excel.lència de les classes populars: Pulcinella. L'antic regne de Nàpols, integrat per Ferran el Catòlic a la llavors federació hispànica (1501) — després, amb els Felips (II i sobretot $\mathrm{V})$, convertida en una esterilitzant «unidad de destino en lo universal»—, va reaccionar a la inevitable dominació militar amb l'única arma que les classes subal- 
ternes poden esgrimir contra el poder i la guerra: la paròdia. Pulcinella neix com a servent de l'aflautat i fatxenda "Capitano Spagnuolo» o "Matamoros», i assumeix l'hostilitat popular envers la soldadesca estrangera. Pulcinella, fent burla de la màscara ridícula del fanfarró, encarna els trets fonamentals de la cultura napolitana: aquell esperit barroc associat al patetisme però a la vegada a la ironia i la befa; aquella carnalitat una mica ambigua i obsessiva, entre l'escatologia i l'obscenitat; aquella gestualitat vivaç, eloqüent i expressiva; aquella manera desmesurada de parlar i de cridar; aquella familiaritat amb la mort i amb els sants. Pulcinella és un personatge ambivalent, limítrof, entre la beneiteria i l'astúcia, dotat d'una prodigiosa loquacitat corporal i un repertori de trucs i de tècniques que han arribat, diversament reinterpretats, fins als nostres dies. La ininterrompuda transmissió va tenir el seu moment àlgid al segle XIX amb Antonio Petito (1822-1876), autor, actor, cantant, mim, ballarí, acròbata, prestidigitador i músic, que va amarar Pulcinella de bons sentiments i solidaritat amb les capes populars.

Deixeble i hereu rebel de Petito va ser Eduardo Scarpetta (1853-1925), autor $\mathrm{i}$ intèrpret que va actualitzar Pulcinella amb la creació d'una nova màscara adaptada als nous temps del triomf de la burgesia urbana: el personatge Felice Sciosciammocca, protagonista de Mettiteve a fá l'ammore cu 'mme!, farsa que es va representar el 2004 a l'Ateneu barceloní en la primera edició d' «Els Napolitans», sota la batuta d'Arturo Cirillo al capdavant de la companyia Nuovo Teatro Nuovo. De Filippo, el fill no reconegut de Scarpetta, va reinterpretar l'etern Pulcinella en recuperar el repertori patern, lubrificant així la màquina còmica de l'esperit napolità. Son germà Peppino, en tàndem amb Totò, va portar a les últimes conseqüències gags d'elevada potencialitat comicolingüística, com el de l'escriptura d'una carta a quatre mans que esdevindria model de l'últim gran Pulcinella partenopeu: Massimo Troisi (Il viaggio di Capitan Fracassa, Ettore Scola, 1990).

Això lliga amb una altra qüestió fonamental: la dialèctica entre tradició i modernitat que ha presidit tot el teatre d'Eduardo De Filippo s'inscriu plenament en la gran tradició còmica del teatre occidental: la commedia dell'arte, una tradició fonamentalment actoral, que a Nàpols era ben viva a principis del segle XX, quan Picasso i Stravinsky encara la van poder flairar en el viatge que van fer amb Diagilev i els seus Ballets Russos, experiència de la qual sorgiria el ballet Pulcinella (música de Stravinsky sobre partitures inèdites de Scarlatti trobades a l'Arxiu de Nàpols, i decorats i vestuari de Picasso). Però alhora el seu teatre, prenent peu d'aquesta tradició i assumint els procediments artesanals i les formes consuetes, planteja continguts i personatges de gran modernitat.

\section{Naturalesa de l'escriptura dramàtica d'Eduardo}

De Filippo, com Shakespeare, Molière o Dario Fo, escrivia les seves peces des de l'escenari. Com a home de teatre complet, tenia molt en compte tots els components de l'espectacle i inscrivia el procés de creació textual dintre la 
dinàmica dels assaigs a escena, ajustant, canviant, retallant o afegint segons les necessitats de la companyia o els resultats de la interpretació i les seves condicions expressives. Una pràctica que duen a terme els autors contemporanis com Bob Wilson, Heiner Müller, Richard Foreman o David Mamet. Recordem que Bob Wilson deia: «Escriure un espectacle és crear amb qui el representa. La carcassa de l'espectacle la dóna el treball que es fa amb actors", mentre que Foreman busca l'equivalència entre textos visuals, espacials i verbals, és a dir, establint la paritat entre els distints components de l'espectacle. No una altra cosa feia De Filippo amb la seva companyia quasi familiar (amb Peppino i Titina).

Per cert, que la nova dramatúrgia catalana participa també d'aquesta autoria compromesa amb l'espectacle, que trepitja l'escenari, que s'embruta les mans en l'elaboració dels espectacles i que s'implica plenament en el procés creatiu de l'escenificació. Una implicació que, lògicament, ha comportat una transformació de l'escriptura teatral, que d'una banda s'ha alliberat de ràncies convencions i de l'altra ha posat en quiestió els procediments en ús com el diàleg, les coordenades tempoespacials, el conflicte dramàtic, la noció de personatge, en un procés de depuració i desconstrucció del llenguatge i de les estratègies textuals tradicionals. I, en efecte, en la dramatúrgia catalana d'avui constatem l'emergència d'aquesta nova tipologia autoral: autors que no s'han quedat en la faceta purament textual, sinó que alhora dirigeixen; d'altres que freqüenten simultàniament l'escriptura dramàtica i la interpretació actoral, i d'altres encara que escriuen, interpreten i dirigeixen els seus espectacles.

\section{Influència de De Filippo en el teatre català actual}

La més rotunda influència de l'obra de De Filippo en la dramatúrgia catalana d'avui la trobem en Sergi Belbel, sens dubte l'autor teatral més important de la península Ibèrica i el millor portaveu del teatre català al món. La traducció i la posada en escena de Dissabte, diumenge $i$ dilluns han deixat una singular empremta en el nostre dramaturg, que és un dels exemples més brillants d'autor-esponja, com també ho fou De Filippo, i, també com ell, preocupat per dur a terme un teatre popular que interessi el públic majoritari, un teatre que creï emocions i que consideri l'espectador un component essencial del fet escènic.

Belbel va començar la seva fulgurant carrera teatral de la mà de Beckett $\mathrm{i}$ Koltés, als quals també traduí i adaptà a la seva personal dicció, sense oblidar aspectes de Bernhard, Mamet, Müller i Shepard. En un primer moment, doncs, l'obra de Belbel va enlluernar per la seva modernitat estructural i la seva investigació formal, amb tota mena de jocs temporals i espacials, de mecanismes, recursos i resolucions d'autèntica mestria. Ara bé, li trobàvem a faltar una certa manca de profunditat en el dibuix dels personatges i en l'anàlisi dels continguts, i també una certa manca de posicionament o de compromís amb els temes exposats. Aspectes que sí que trobem en la seva última peça (la vintena), Forasters, estrenada l'any passat després de dues temporades representant De Filippo, i on tracta una història de família d'allò més sòrdida. Es tracta de l'obra 
més ambiciosa que li coneixem, d'una considerable complexitat especialment en el tractament temporal de l'acció, que es desenvolupa alhora als anys 1960 i als 2000, en una superposició de papers i rols entre els distints membres d'un clan familiar i els seus veïns immigrants (primer interiors, com la família andalusa del mateix Belbel; després exteriors, nord-africans).

Belbel s'atreveix a resseguir amb un traç de fondària els perfils de la tragèdia, ni que sigui sota l'aparença del melodrama (el subtítol és «melodrama familiar en dos temps»), i gosa construir personatges de gruix, de profunditat psicològica, lluny de la trivialitat contemporània, on la malaltia terminal (càncer) que empeny el clan cap a l'extinció esdevé metàfora de la podridura de la civilització europea, precipitada amb l'arribada de la nova població d'immigrants. Així doncs, els vincles familiars erosionats, deteriorats, són un tema recurrent en el teatre de De Filippo, com també ho són els efectes de fantasmagoria teatral que es produeixen per l'ambivalència dels personatges, quan els pares dels anys seixanta s'emmirallen en els fills dels 2000, en una subtil relació entre vius i morts on els fantasmes del passat ressorgeixen amb força.

Forasters és un drama esquinçat, d'una gran força expressiva, que aprofundeix en la condició humana, amb les seves misèries més sòrdides, les malalties, la mort, i on la memòria adquireix una dimensió històrica com a memòria de tota una cultura, un país, una civilització. Al clatell de l'obra s'hi condensa el càlid alè d'Eduardo. 